Iran Journal of Nursing (IJN)

Vol 32, No. 121, Dec 2019: 1- 13

\title{
Medication Errors in Intensive Care Units in the Viewpoint of Nurses: A
}

\section{Descriptive Study}

\author{
Monireh Ghanbari Afra ${ }^{1}$, Jaleh Mohammad Aliha², Marjan Mardani Hamooleh ${ }^{3}$ \\ Leila Ghanbari Afra ${ }^{4}$, Shima Haghani ${ }^{5}$
}

\begin{abstract}
Background \& Aims: Among healthcare professionals, nurses spend the most time with patients and monitor them throughout the medication process from the time of admission until discharge. Since nurses are responsible for the direct care of patients and participate in their medication process, the risk of medication errors by nurses increases. The process of medication involves prescription, copying the instructions of physicians, medication distribution, delivery of medication to the patient, and medication control. Failure in any of the mentioned stages is referred to as medication error. In the nursing profession, medication errors include the incorrect dosage of medication, elimination of medication, negligence of the symptoms of drug poisoning, and choosing the wrong site for the administration of medication. Medication error is a preventable incident, which could cause damage to the patient if not managed. The patients admitted to intensive care units (ICUs) receive more drugs compared to the patients admitted to other wards. Furthermore, due to drowsiness or unconsciousness, the process of patient identification and monitoring of drug side-effects in these patients is associated with more challenges in these patients. The importance of medication errors is considered in terms of consequences such as increased disabilities, patient dissatisfaction with healthcare systems, increased length of hospital stay, and increased treatment costs. ICU nurses experience higher stress levels due to special working conditions, such as heavy workload, the need to respond quickly to emergency situations, heavy responsibility of the care of critically ill patients, frequent encounters with emotional situations, and being in unwanted and enforced situations for delivering unpleasant news to patients' families. The present study aimed to determine the causes of the incidence of medication errors, their lack of reporting, and their frequency in ICUs.

Materials \& Methods: This cross-sectional, descriptive study was conducted on 300 ICU and CCU nurses in three teaching hospitals affiliated to Qom University of Medical Sciences in Qom, Iran in 2019. The subjects were selected via census sampling. Data were collected using a demographic questionnaire to determine the variables of age, gender, marital status, education level, ward of employment, work shift, nursing experience, work experience in the current ward, type of employment, number of overtime hours per month, overtime work in one/more hospitals, other overtime work than nursing, number of the working hours per week, and valid and reliable tool of medication errors. The content validity method was used to assess the validity of the tool, which was provided to five nursing professors at Iran University of Medical Sciences (IUMS), and their corrective comments were applied. The Cronbach's alpha coefficient was also used to measure the reliability of the tool. For this purpose, 15 nurses who matched the research samples and were not members of the research units completed the tool in one turn. Data analysis was performed in SPSS version 21 using descriptive statistics (percentage, frequency, mean, and standard deviation) and inferential statistics (analysis of variance and independent t-test), and the P-value of less than 0.05 was considered significant. The ethics code of the study was IR.IUMS.REC 1397.102. In order to comply with ethical considerations, a written letter of introduction was obtained from IUMS to perform the research at Qom University of Medical Sciences. In addition, the nurses were enrolled after obtaining written consent and were assured of the confidentiality of their responses in the questionnaires without mention.
\end{abstract}

\footnotetext{
1. MS in Critical Care Nursing, Shahid Beheshti Hospital, Qom University of Medical Sciences, Qom, Iran

2. Lecturer, School of Nursing and Midwifery, Iran University of Medical Sciences, Tehran, Iran

${ }^{3}$. Assistant Professor, Nursing Care Research Center, Department of Psychiatric Nursing, Iran University of Medical Sciences, Tehran, Iran (Corresponding author) Tel: 09132864077 Email: mardanimarjan@gmail.com

${ }^{4}$. MS in Critical Care Nursing, Kamkar Hospital, Qom University of Medical Sciences, Qom, Iran

5. MS in Biostatistics, Nursing Care Research Center, Iran University of Medical Sciences, Tehran, Iran
} 
Results: Systemic errors (mean score: $4.1 \pm 1.2$ ) and pharmacy errors (mean score: $2.5 \pm 1.1$ ) had the highest and lowest mean scores among the causes of medication errors, respectively. Furthermore, managerial causes with the mean score of $3.8 \pm 1$ and causes associated with disagreement with the mean score of $2.6 \pm 1.1$ had the highest and lowest mean scores among the causes of the non-reporting of medication errors, respectively. Intravenous errors $(22.56 \%)$ had a higher frequency compared to non-intravenous errors $(21.89 \%)$. Among the demographic variables, significant correlations were observed medications errors with age $(\mathrm{P}=0.029)$ and work experience in the current ward $(\mathrm{P}=0.007)$ according to the analysis of variance.

Conclusion: According to the results, the highest to lowest mean scores of the causes of medication errors belonged to systemic causes, drug packaging, medical and nursing causes, document registration, and pharmacy causes, respectively. Among the demographic variables, significant correlations were denoted between medication errors, ICU work experience, and age, so that with the increased work experience and age of the nurses, the incidence of medication errors would decrease. It seems that the increased calendar age and working age resulted in their increased dominance over the work environment, so that the incidence of medication errors would decrease. Therefore, it could be stated that knowledge of the influential factors in the incidence of medication errors is essential to the development of proper strategies by nurses to prevent these errors. In this regard, it is critical that special attention be paid by nursing managers to proposing strategies to enhance the knowledge of nurses regarding medication errors in order to reduce these errors through holding clinical management workshops based on the approach of medication errors, accompanied by obtaining points from the continuous education system for nurses. The results of this study indicated that in order to reduce the incidence of errors by nurses, it is necessary to create the conditions to reduce systemic errors in hospitals. In addition, it is imperative for nursing managers to lay the foundations for nurses to report their errors. On the other hand, nursing managers should closely monitor the administration of medications by nurses, especially in the case of intravenous medications. Since the findings of this study were obtained using a questionnaire, the perceptions of nurses toward medication errors could not be assessed in depth. Therefore, it is suggested that studies with a qualitative approach be performed in order to achieve a complete picture of this concept. Furthermore, the results of this study could lay the groundwork for interventional studies to reduce the incidence of medication errors for nurses.

Keywords: Medication Errors, Nurse, Intensive Care Unit

\section{Conflict of Interest: No}

How to Cite: Ghanbari Afra M, Mohammad Aliha J, Mardani Hamooleh M, Ghanbari Afra L, Haghani SH. Medication Errors in Intensive Care Units in the Viewpoint of Nurses: A Descriptive Study. Iran Journal of Nursing. 2019; 32(121):1-13.

Received: 2 Sep 2019

Accepted: 2 Dec 2019 


\title{
وقوع خطاهاى دارويى در بخشهاى مراقبت ويزه از ديدكاه برستاران: يك مطالعه توصيفى
}

\author{
منيره قنبرى افرا'، زاله محمدعليها'، مرجان مردانى حموله"، ليلا قنبرى افراءُ، شيما حقانى
}

جكکنه

زمينه و هدف: خطاهاى دارويى يكى از شايعترين خطاها در يرستارى بالينى به شمار مى آيند. اين مطالعه با هدف تعيين دلايل وقوع خطاهاى دارويى،

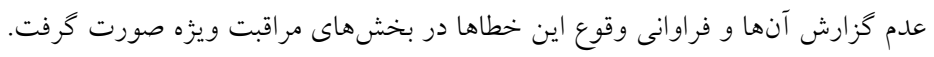

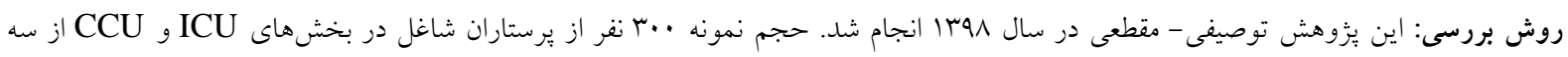

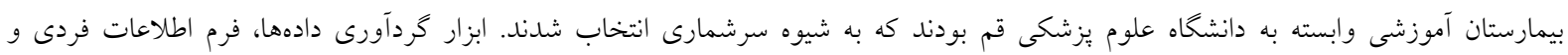

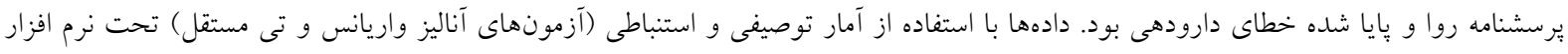
SPSS

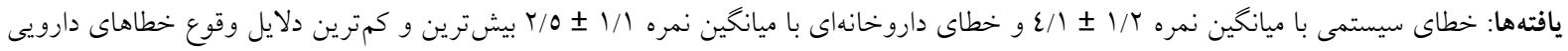

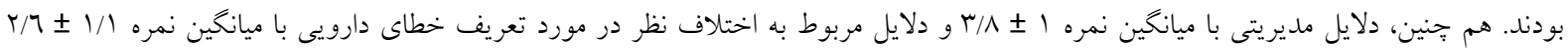

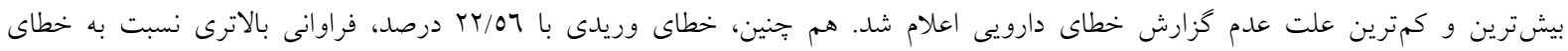

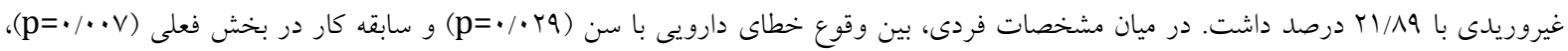

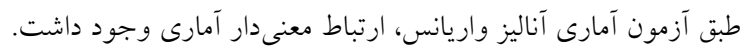

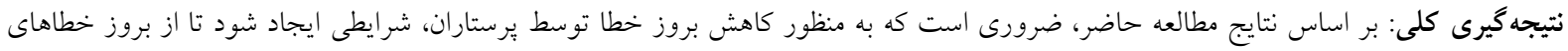

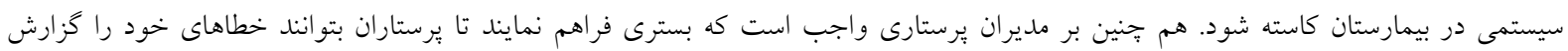

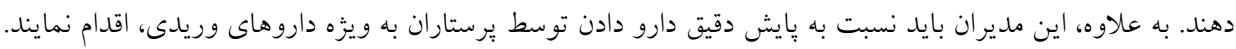
كليل وازهها: خطاهاى دارويى، برستار، بخش مراقبت ويزٌ تاريخ دريافت منافع: ندارد

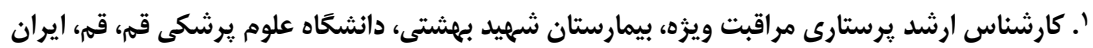

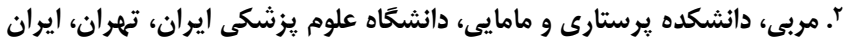

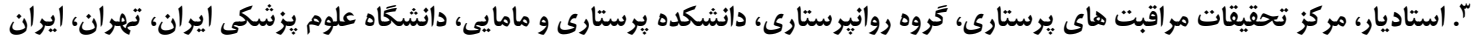
Email:mardanimarjan@gmail.com (نويسنده مسئول) شماره تماس:VV

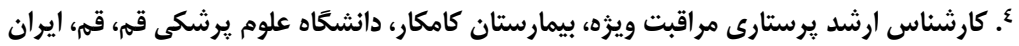

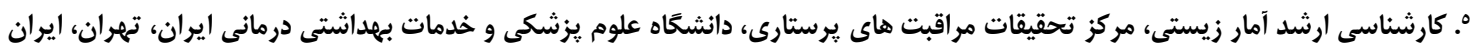


خطاى دارويى، يكى از حوادث قابل بيشخيرى است كه

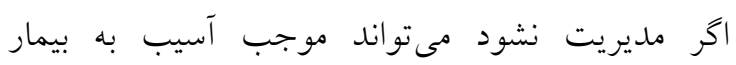

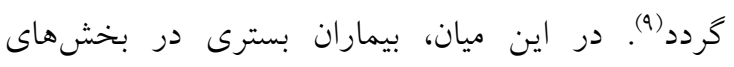

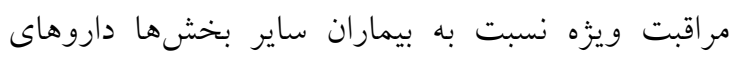

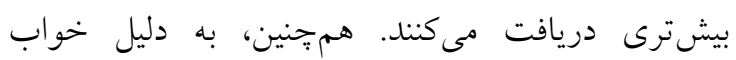

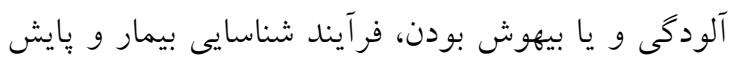

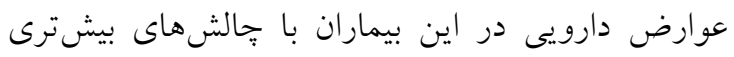
همراه است (r). اهميت خطاهاى دارويى با در نظر داشتن تبعاتى مثل افزايش ناتوانىها، نارضايتى بيماران از نظام هاى ارائه دهنده خدمات سلامت، افزايش طول مدت بسترى و افزايش هزينهاى درمان، مطرح مى كردد (11،.1.).

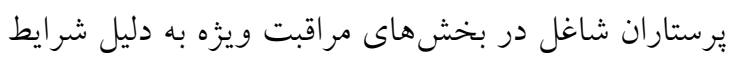

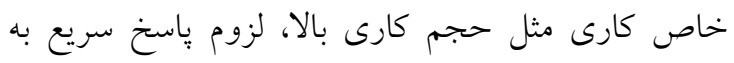

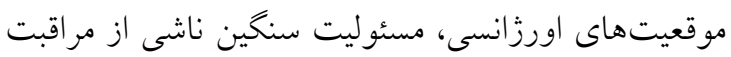

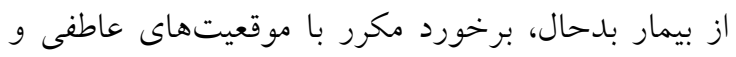

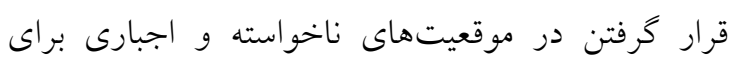

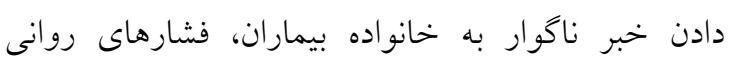

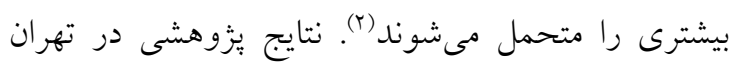

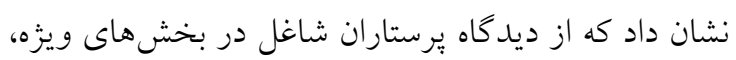

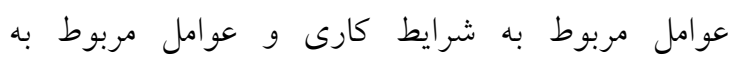

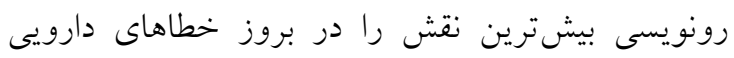
دارد و مهمترين علل خطاهاى دارويى عبارت از عوامل

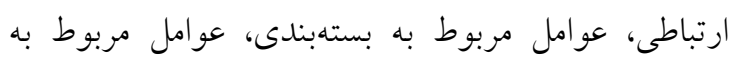

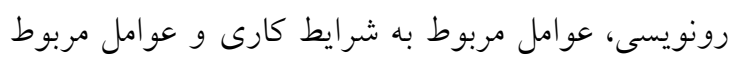

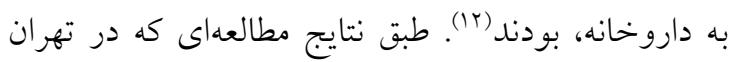

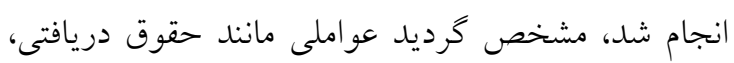
سابقه كار بالينى، نارسايى شناختى، عوامل استرسزاى

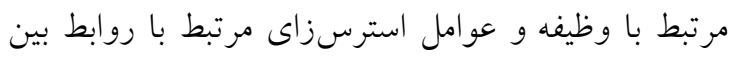
فردى از عوامل مرتبط در بروز خطاهاى بالينى برستاران

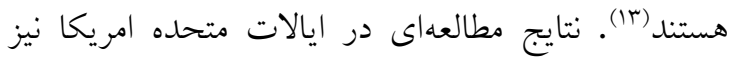
نشان داد كه اختلال در سلامت جسمى و روانى يرستاران

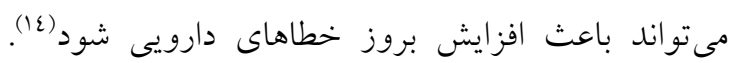

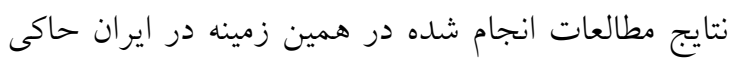

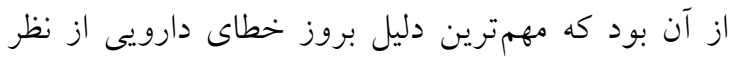

\section{مقدمه}

بخش مراقبت ويزٔه بخشى از بيمارستان است كه در آن

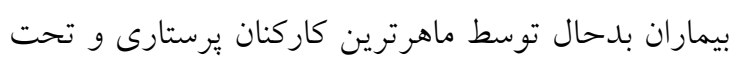

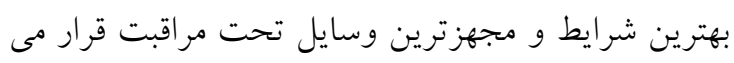

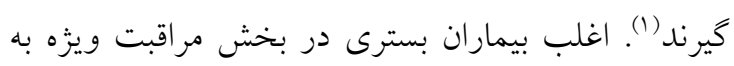
علت شرايط بحرانى داراى وضعيت نايايدارى هستند. بنابراين توجه به كيفيت مراقبت و ايمنى اين بيماران

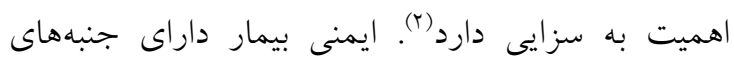
مختلفى است كه رعايت تمامى اين جنبها منجر به

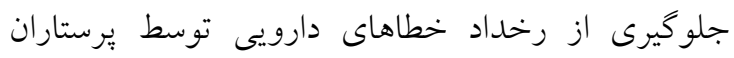

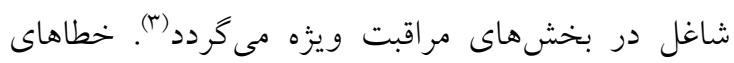

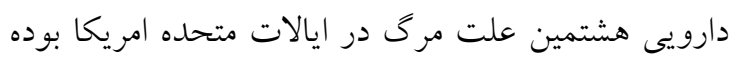

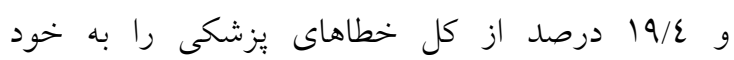
اختصاص مى دهد. به علاوه، در اين كشور، سالانه بيش از

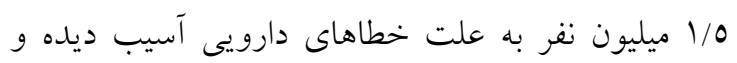

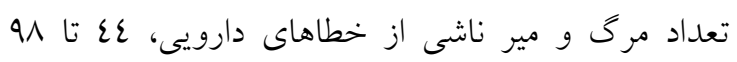

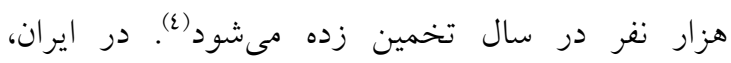
خطاهاى دارويى سالانه ميلياردها تومان هزينه به سيستم سلامت تحميل مىنمايند (r).

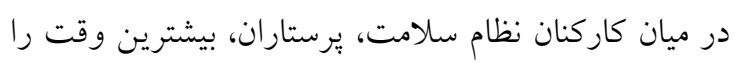

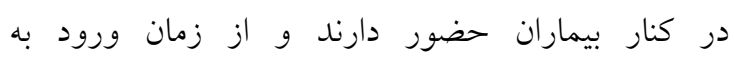
بيمارستان تا ترخيص، آنان را در تمام طول فرآيند دارو

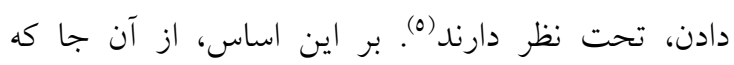
يرستاران مسئول مراقبت مستقيم از بيمار بوده و در فرآيند دارودهى به وى سهيم هستند، اين مهم مى تواند زمينه ساز

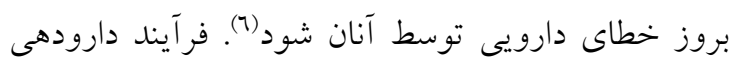

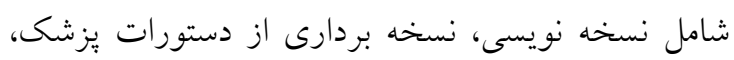

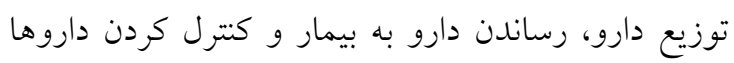

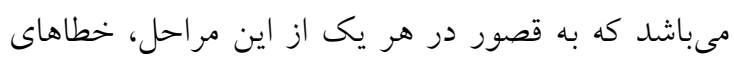

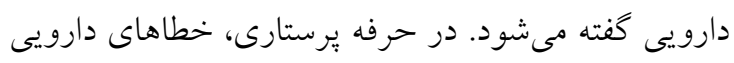

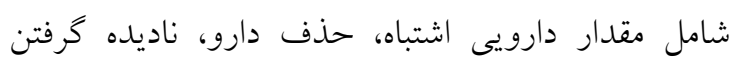
علايم مسموميت دارو و انتخاب محل نادرست در زمان

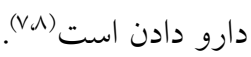


نكردن زمان مناسب دارو ( 1 درصد) و بيشترين گزارش

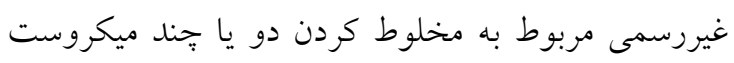

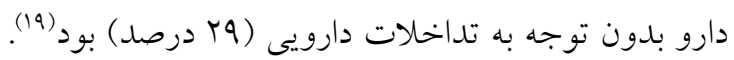

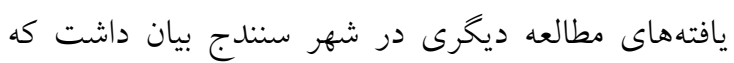
فراوانترين خطاى دارويى يرستاران شامل بيمار اشتباه

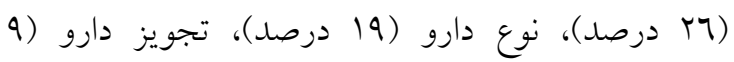
درصد) و مقدار و زمان دارو (rا درصد) بوده است (r.). براى بيماران بسترى در بخشهاى مراقبت ويزه به ازاى

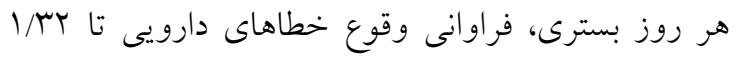

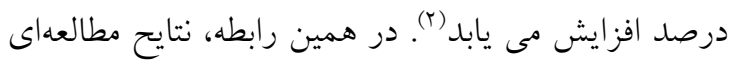

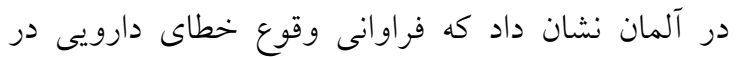

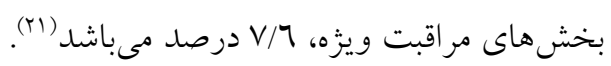

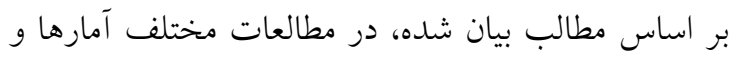
نتايج متفاوتى در خصوص خطاهاى دارودهى بيان شده است كه اين تفاوتها ممكن است به علت دقت به به كار

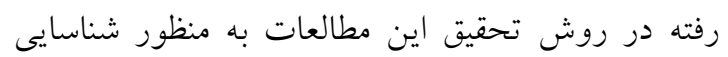
دلايل خطاها و دلايل عدم گزارش دهى دئ آنها يا مكان جغرافيايى انجام تحقيق باشد. اين امر ضرورت اندام انجام

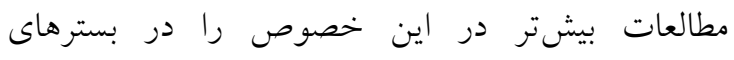

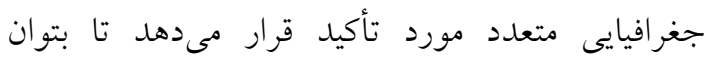
خطاهاى دارويى را بهتر شناسايى نمود. نتايج يك مطالعه

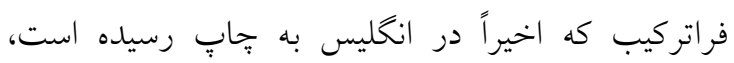
حاكى از آن است كه تجربه خطاهاى دارويى توسط لته

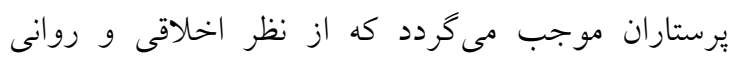

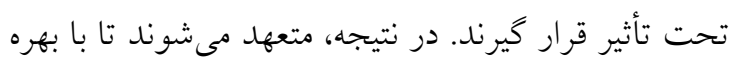
گيرى از راهبردهاى مقابلهاى از بروز خطا در آينده،

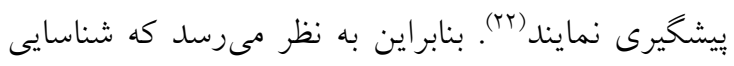

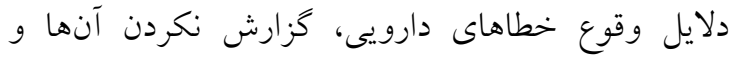
فراوانى وقوع اين خطاها به خصوص از ديد دُعاه يرستاران شاغل در بخشهاى مراقبت ويزه، نقش مهمى در

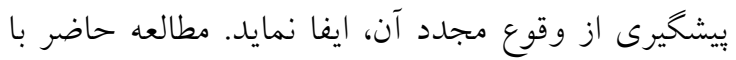
هدف تعيين دلايل وقوع خطاهاى دارويى، كزارش نكردن

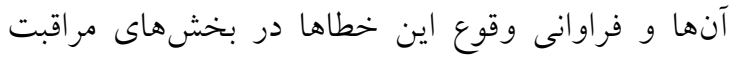
ويزه شهر قم صورت كرفت.
״رستاران به ترتيب شامل باركارى زياد، انجام كار خارج

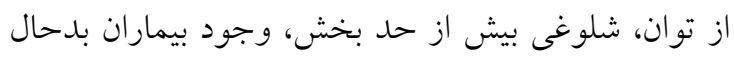

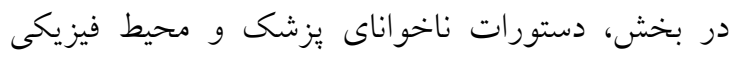

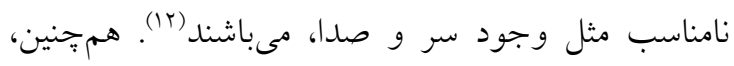
يافتهاى مطالعه ديخرى در داخل كشور نشان داد كه ونه

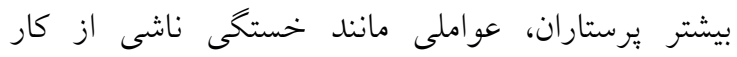
اضافى، كمبود تعداد يرستاران نسبت به تعداد بيماران در بخش، مشكلات روانى يرستار، ناخوانا بودن دستور

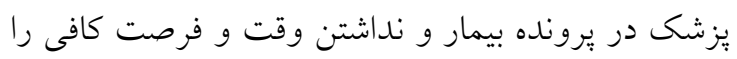
از مهمترين دلايل بروز خطاهاى دارويى ذكر كردند (10). از سوى ديخر، گزارش خطاى دارويى توسط برستاران، نقش مهمى در جلوگيرى از كسترش آن دارد و كيفيت

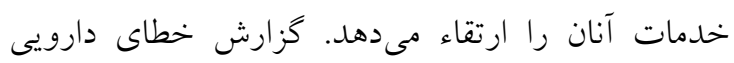
توسط يرستاران در اتيويى، OV/2 درصد و در حد بالا فرالا

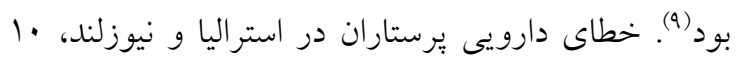

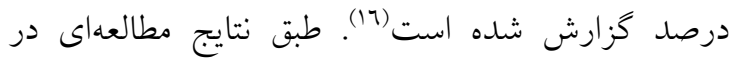

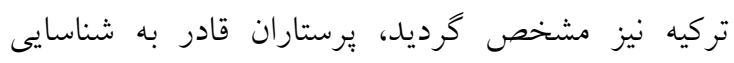

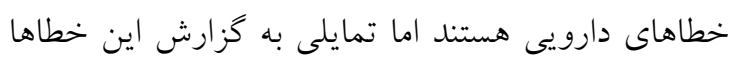

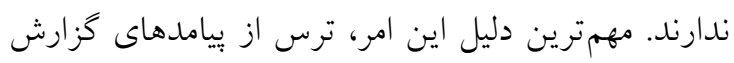

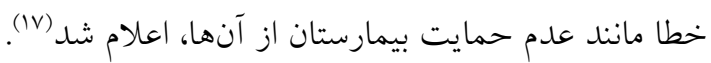
عامل مهم ديخرى كه در زمينه خطاهاى دارودهى توسط مانس

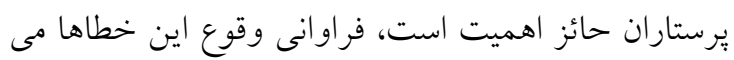

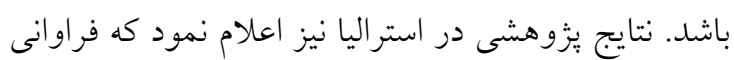

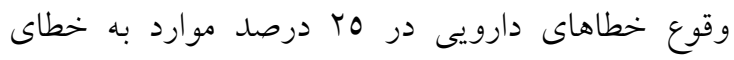

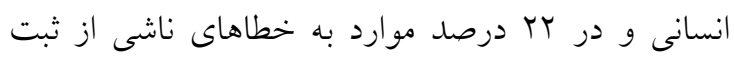

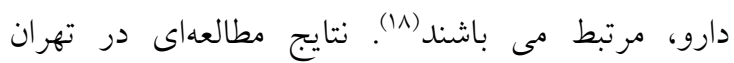

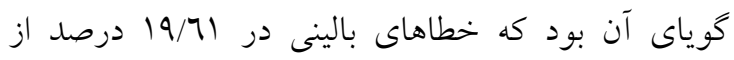

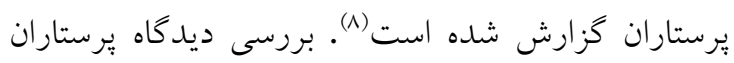
شهر اصفهان نشان داد، وقوع خطاهاى دارويى توسط آنان 77/1 درصد بوده است كه در اين ميان، گزارشدهى

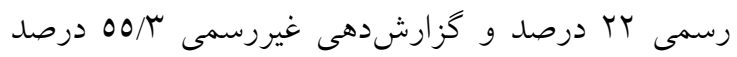
را به خود اختصاص داده است. بيشترين فراوانى خطاها V.) مربوط به دادن دارو ديرتر يا زودتر از زمان مقرر درصد)، بيشترين گزارش رسمى مربوط به رعايت 
در يكى يا جند بيمارستان، اضافه كارى غير از كار

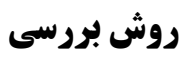

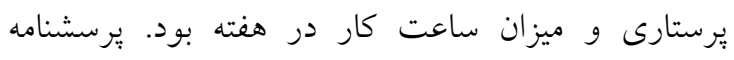

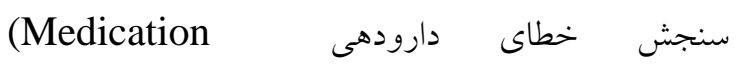
توسط Adminstriation Error MAE) و همكاران در سه خرده مقياس طراحى توسط

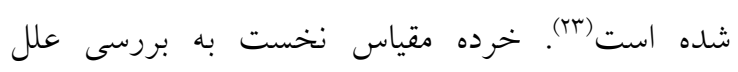

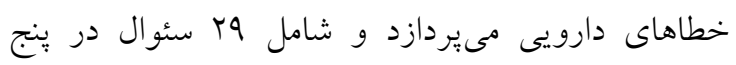

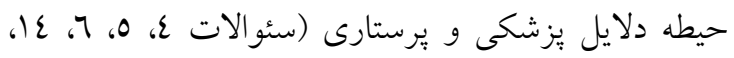

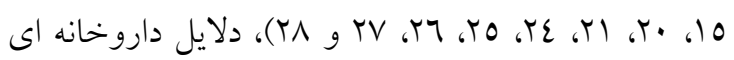

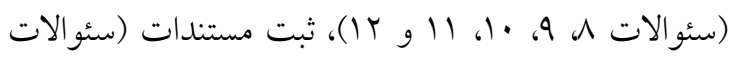

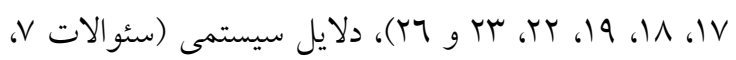

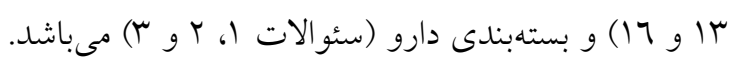
هاسخ كويى به اين بخش به صورت شديداً مخالفم، نسبتاً مخالفم، كمى مخالفم، كمى موافقم، نسبتاً موافقم و شديداً

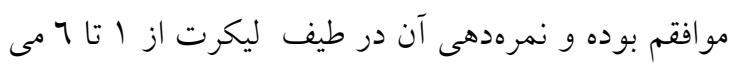

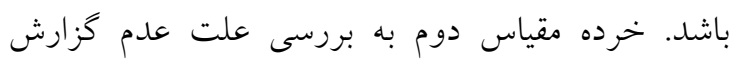

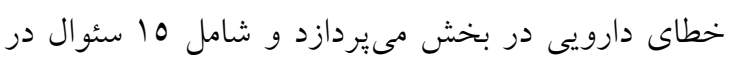

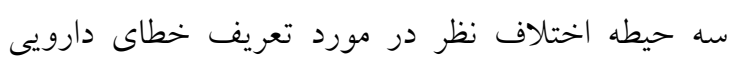

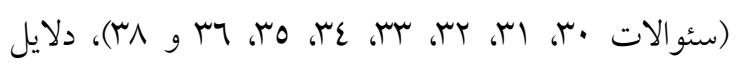

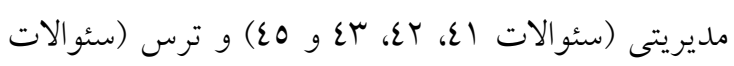

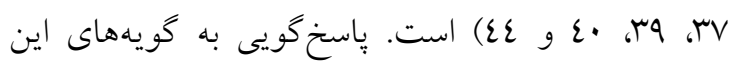
بخش نيز به صورت بخش نخست مىباشد. در هر يكى از

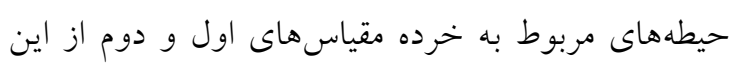

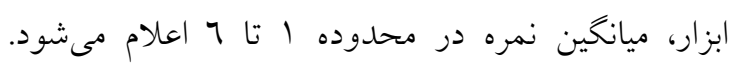

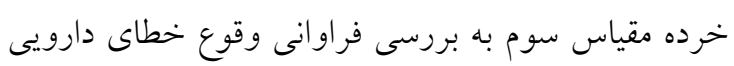

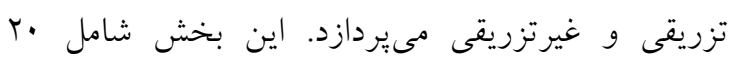

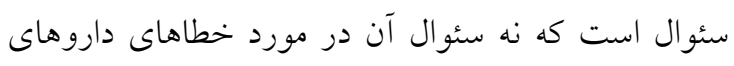

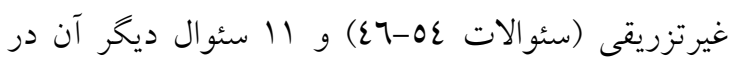

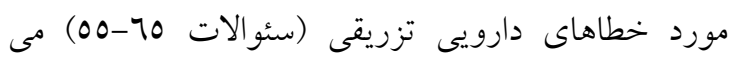

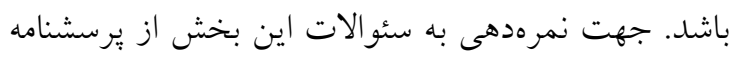

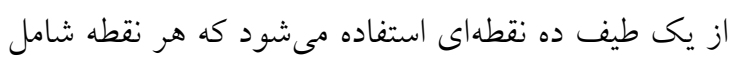

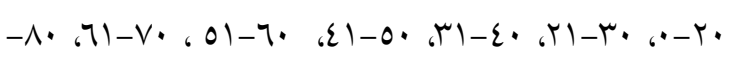

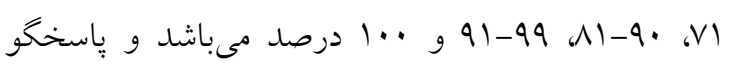
با مشخص كردن نقطه مورد نظر، درصد وقوع خطا را

اين مطالعه، يكى مطالعه توصيفى - مقطعى بود كه در سال

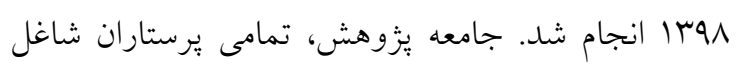

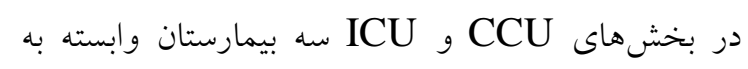
دانشخاه علوم بزشكى قم بود. طبق آمار كرفته از معاونت

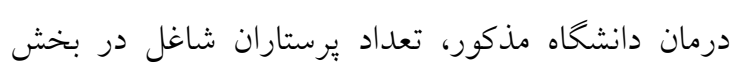

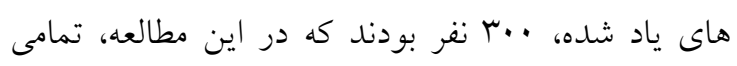
يرستاران با روش سرشمارى وارد مطالعه شدند. معيار

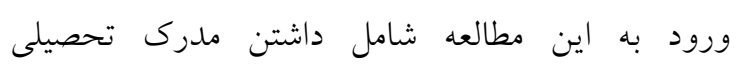
كارشناسى و كارشناسى ارشد يُرستارى و اشتغال به كار

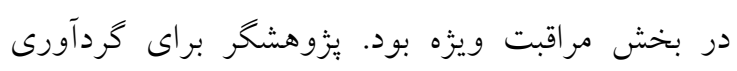

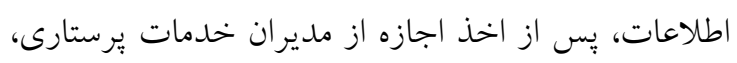

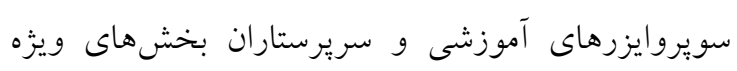
طى روزهاى مختلف در بيمارستانهاى مذكور حضور

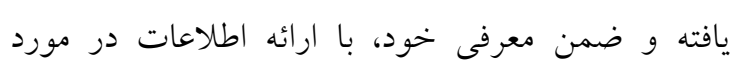

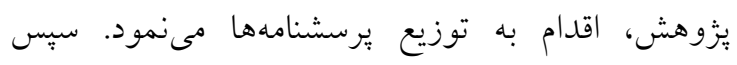

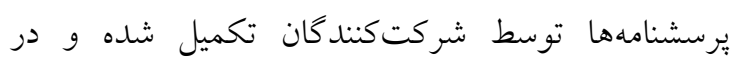

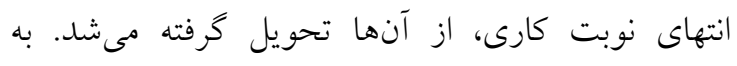

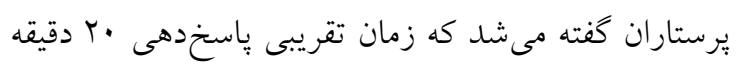

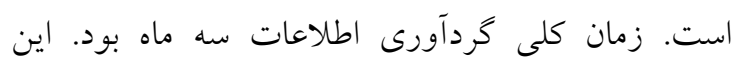
IR.IUMS.REC مطالعه داراى كد اخلاق 1397.102

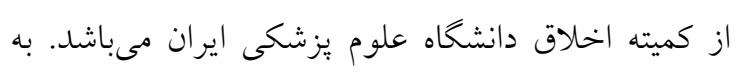
منظور رعايت ملاحظات اخلاقى، معرفى نامه كتبى از

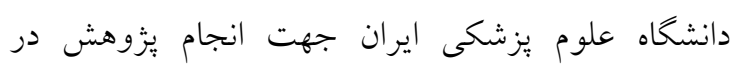

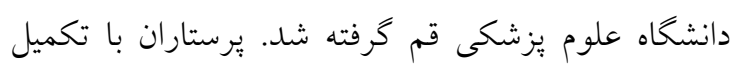
رضايتنامه كتبى وارد مطالعه شدند و به آنان اطمينان داده شد كه پاسخخهاى مندرج در يرسشنامها، محرمانه خو اهند بود و نيازى به ذكر در برسشنامه نيست.

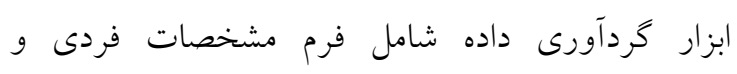

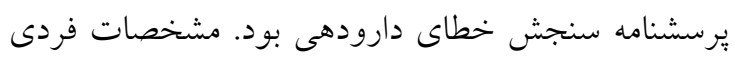

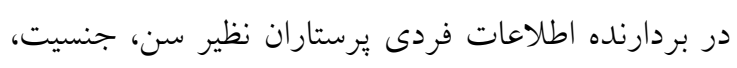
وضعيت تأهل، سطح تحصيلات، بخش محل كار، شيفت

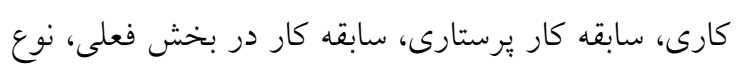

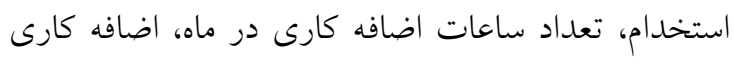


كزارش خطا در حيطه اختلاف نظر /N/ •، دلايل مديريتى

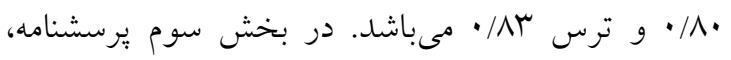

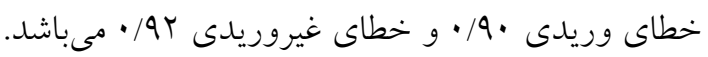

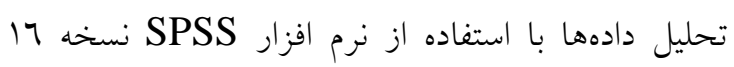

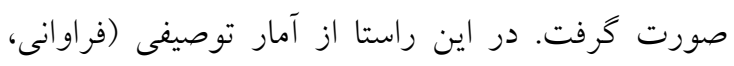

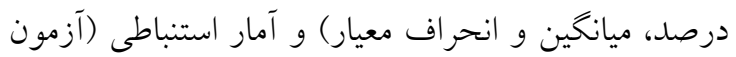

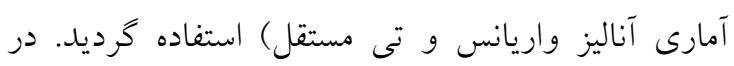
تحليل دادهها نيز P-value كمتر از ه • معنى دار در نظر كرفته شد.

\section{بافتهها}

شاخصهاى عددى خطاى دارودهى يرستاران بر حسب

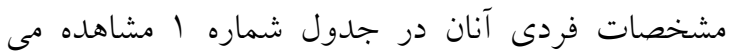
شود. خطاى سيستمى با ميانخين نمره 1/r

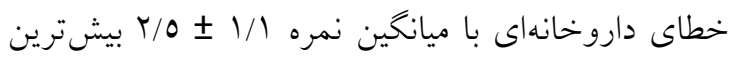
و كمترين خطاهاى دارويى بودند.
بيان مىنمايد. بديهى است كه جهت سئوالات بخش سوم، نمى توان ميانخين نمره اعلام نمود.

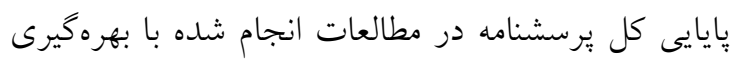

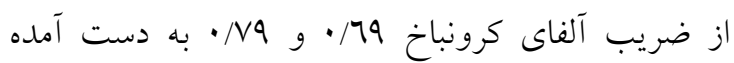

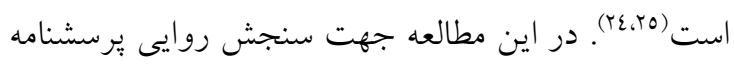

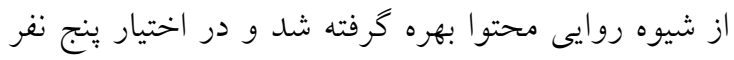

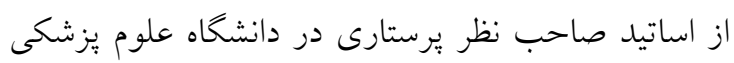
ايران قرار كرفت و سبس نظرات اصلاحى آنها اعمال

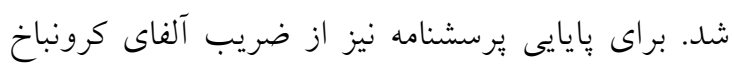

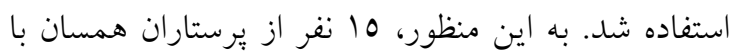
نمونه يزوهش كه عضو نمونههاى تحقيق نبودند، طى يك نوبت، يرسشنامه را تكميل نمودند. ضريب آلفاى كرونباخ براى هر يك از خرده مقياسها به اين شرح حاصل شد. در خرده مقياس علل خطا، دلايل بروز خطاهاى دارويى در حيطه يزشكى و يرستارى 19/،، دلايل داروخانهاى

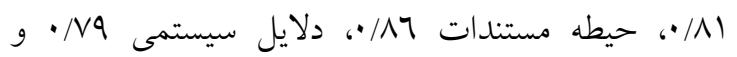
بسته بندى داروها 10/· و در خردها مقياس دلايل عدم

جدول شماره ا: شاخصهاى عددى خطاى دارودهى يرستاران برحسب مشخصات فردى آنان

\begin{tabular}{|c|c|c|c|c|c|c|}
\hline نتيجه آزمون & انحر اف معيار & ميانخين & درصد & فراوانى & مشخصات فردى & \\
\hline $\mathrm{F}=1 / \cdot 19$ & IT/NT & OY/VE & $r q / r$ & $M$ & كمتر از •r & \\
\hline \multirow[t]{2}{*}{$* P=\cdot / \cdot r q$} & $1 \varepsilon / \cdot 9$ & $0 T / v 0$ & $\varepsilon 7$ & וr & $r \cdot-r q$ & سن (سال) \\
\hline & $10 / 47$ & $01 / 11$ & $r \varepsilon / V$ & $v \varepsilon$ & •ع و بالاتر & \\
\hline$t=\cdot / V \varepsilon r$ & $10 / 11$ & OE/LY & $r q / r$ & 111 & مرد & جنسيت \\
\hline $\mathrm{P}=\cdot / 20 \wedge$ & $19 / 11$ & $0 \varepsilon / 91$ & $7 \cdot / V$ & int & زن & \\
\hline$t=\cdot / 0 r r$ & $10 / T V$ & $O Y / \Lambda I$ & $\varepsilon r / V$ & IYN & مجرد & وضعيت تأهل \\
\hline $\mathrm{P}=\cdot / 09 \varepsilon$ & $1 \varepsilon / 79$ & Ar/M & $O V / r$ & IVT & متأهل & \\
\hline$t=\cdot / 9 \vee \wedge$ & $1 \% / 77$ & $0 \varepsilon / 97$ & 94 & TV7 & كارشناسى & سطح تحصيلات \\
\hline $\mathrm{P}=\cdot / \mu T q$ & $17 / T V$ & $0 \varepsilon / \cdot \wedge$ & $\wedge$ & $T \varepsilon$ & كارشناسى ارشد و بالاتر & \\
\hline$t=\cdot / 9 \cdot 0$ & $10 / 7 \mathrm{~V}$ & $O Y / \varepsilon \Lambda$ & TN/V & $r \cdot 7$ & آى سى يو & بخش محل كار \\
\hline $\mathrm{P}=\cdot / / 777$ & $11 / 79$ & $0 T / Y 1$ & m & $9 \varepsilon$ & سى سى يو & \\
\hline$F=I / Y Y Y$ & $\mid r / \varepsilon r$ & $O V / \Gamma \wedge$ & $\wedge$ & r & صبح & \\
\hline \multirow[t]{3}{*}{$\mathrm{P}=\cdot / r q \wedge$} & $10 / 11$ & $0 \varepsilon / \varepsilon$. & r & 7 & عصر & نوبت كارى \\
\hline & $1 \cdot 1 \cdot 9$ & Or/O. & $\mu / \mu$ & 11 & شب & \\
\hline & $11 / 27$ & $0 r / 10$ & $\wedge \mathrm{T} / \mathrm{V}$ & rq. & در گردش & \\
\hline$F=\cdot / 199$ & $1 Y / 79$ & $O \varepsilon / V Y$ & $T V / V$ & N & كمتر از 0 & سابقه كار يرستارى \\
\hline$P=\cdot / q r q$ & $\mid r / \cdot V$ & $00 / 97$ & $I V / T$ & or & Oتا 1 1 & (سال) \\
\hline
\end{tabular}




\begin{tabular}{|c|c|c|c|c|c|c|}
\hline & $1 \varepsilon / \pi q$ & $07 / 9 \varepsilon$ & ro/V & VV & 1. تا 10 & \\
\hline & $\mid V / \varepsilon$ & $0 . / 9 r$ & $I V / r$ & or & 10 تا 19 & \\
\hline & Ir/ro & $0 T / I V$ & ir & ry & 19 و بالاتر & \\
\hline $\mathrm{F}=\cdot / 07 \varepsilon$ & $\mid r / \varepsilon r$ & $O V / T \Lambda$ & $\varepsilon \tau / r$ & $1 \% 9$ & كمتر از 0 & \\
\hline \multirow{3}{*}{$* \mathrm{P}=\cdot / \cdot v$} & $10 / 11$ & $0 \varepsilon / \varepsilon$. & r & 79 & O ت & سابقه كار در بخش فعلى \\
\hline & $1 \cdot 1 \cdot 9$ & $O T / O$. & $1 N / V$ & 07 & . اتا 10 & (سال) \\
\hline & $1 Y / 79$ & $0 \varepsilon / \cdot 0$ & ir & $m$ & 10 و بالاتر & \\
\hline$F=1 / \varepsilon \circ r$ & $10 / 0 Y$ & $0 \varepsilon / \pi 1$ & 07 & 171 & رسمى & \\
\hline \multirow[t]{3}{*}{$\mathrm{P}=\cdot / r \circ \wedge$} & $\mid r / T$ & $0 \varepsilon / 0$ & $9 / r$ & rی & يمانى & نوع استخدام \\
\hline & $|1 / T|$ & $O V / \backslash \varepsilon$ & $I V / r$ & or & قراردادى & \\
\hline & $10 / T V$ & $00 / 11$ & $I V / r$ & or & طرحى & \\
\hline$t=1 / \wedge \varepsilon 7$ & $11 / 79$ & $00 / 71$ & ro & 1.0 & .9 و كمتر & تعداد ساعات اضافه \\
\hline $\mathrm{P}=\cdot / r 77$ & $I V / V \varepsilon$ & $00 / \wedge$ & 70 & 190 & بيشتر از •9 & كارى در ماه \\
\hline$t=1 / \wedge \varepsilon 7$ & IT/N & $O \varepsilon / \varepsilon V$ & $9 V / \pi$ & rar & يك بيمارستان & اضافه كارى در يك يا \\
\hline $\mathrm{P}=\cdot / \varepsilon r\urcorner$ & $1 \varepsilon / \Lambda r$ & $0 r / \cdot 1$ & $r / V$ & $\wedge$ & جند بيمارستان & جند بيمارستان \\
\hline $\mathrm{t}=|/ r| r$ & $\mid \varepsilon / T \varepsilon$ & $0 \varepsilon / 11$ & $r / r$ & v & دارد & اضافه كارى غير از كار \\
\hline $\mathrm{P}=\cdot / r Y 7$ & $17 / 7 \varepsilon$ & $O N / 7 \varepsilon$ & $q \vee / V$ & rar & 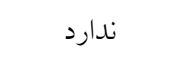 & 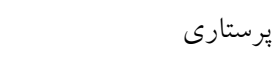 \\
\hline$t=1 / V Y q$ & $1 T / 79$ & $07 / \cdot 0$ & $0 . / r$ & 101 & ل v و كمتر & ميزان ساعت كار در \\
\hline $\mathrm{P}=\cdot / \cdot 10$ & $10 / \mathrm{AV}$ & OY/AV & $\varepsilon q / V$ & $1 \varepsilon 9$ & Vيشتر از V V & 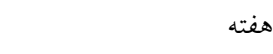 \\
\hline
\end{tabular}

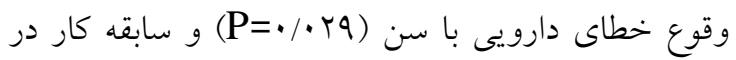

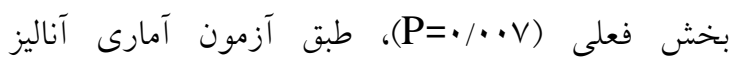
واريانس، ارتباط معنى دار آمارى وجود داشت لهت (يرستاران

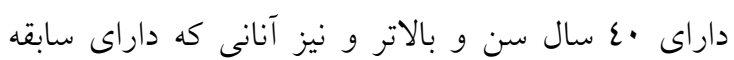
كار 10 سال و بالاتر بودند، كمترين خطاى دار دارويى راسئ كزارش نمودند).
هم جنين، دلايل مديريتى با ميانخين نمره 1 I

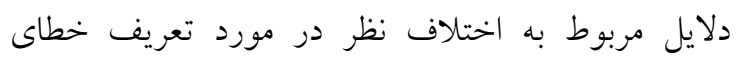

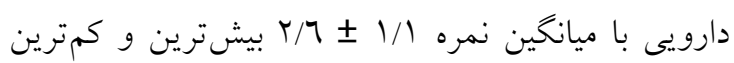

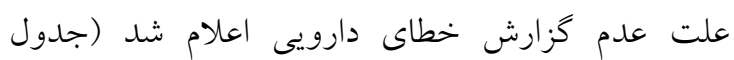
شماره Y). در خصوص فراوانى وقوع خطاى دارويى،

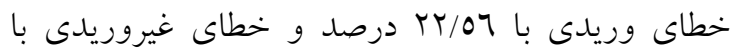

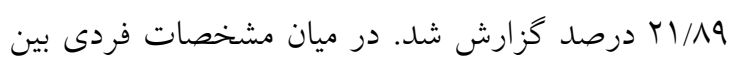

جدول شماره ז: خطاهاى دارويى و دلايل عدم كزارش آنها توسط يرستاران

\begin{tabular}{|c|c|c|c|}
\hline انحر اف معيار & & خطاى دارويى & \\
\hline $1 / r$ & $\varepsilon / 1$ & دلايل سيستمى & \multirow{5}{*}{ دلايل وقوع خطاى دارويى } \\
\hline $1 / r$ & $r / \mathrm{V}$ & بسته بندى دارو & \\
\hline 1 & $\mu / \tau$ & دلايل يزشكى و برستارى & \\
\hline $1 / r$ & $r / 1$ & 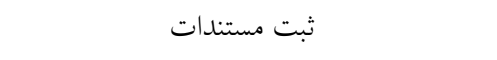 & \\
\hline $1 / 1$ & $r / 0$ & دلايل داروخانهاى & \\
\hline 1 & $\Gamma / \Lambda$ & دلايل مديريتى & \multirow{3}{*}{ لايل گزارش نكردن خطا. } \\
\hline $1 / 1$ & $\Gamma / 0$ & ترس & \\
\hline $1 / 1$ & $r / 7$ & اختلاف نظر در مورد تعريف خطاى دارويى & \\
\hline
\end{tabular}


بر اساس يافتهاى به دست آمده از ئزوهش طاهرى و

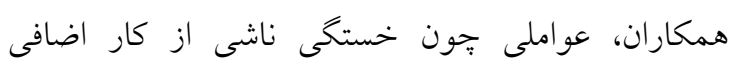

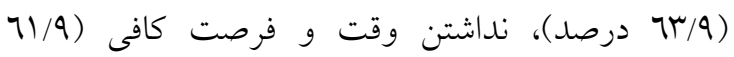
درصد)، كمبود تعداد برستاران در مقايسه با تعداد بيماران بخش (1/1/ درصد)، كمبود دانش دارويى يرستاران

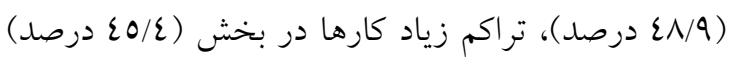

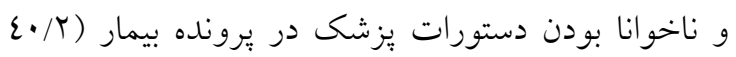

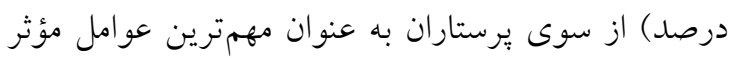
در بروز اشتباهات دارويى ذكر شده اند (rا) كه با نتايج مطالعه حاضر متفاوت است. اين تفاوت مىتواند به علت تفاوت در نوع ابزار استفاده شده در هر دو مطالعه باشد.

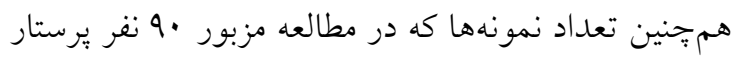
از دو بيمارستان و در مطالعه حاضر ..ب نفر از يرستاران بخشهاى CCU و ICU در سه بيمارستان مورد مطالعه قرار كرفتند. نتايج مطالعه Hammoudi و همكاران نشان داد كه عوامل مؤثر در بروز خطاهاى دارويى به

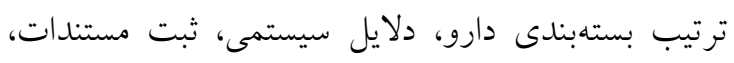

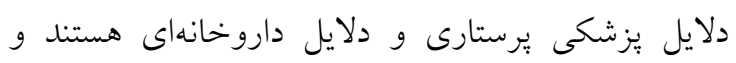

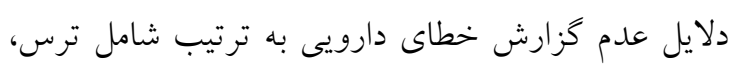

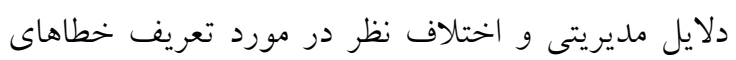

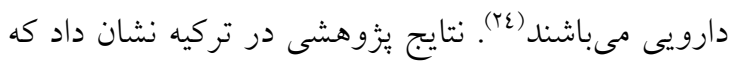

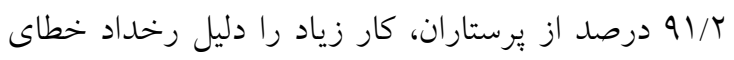

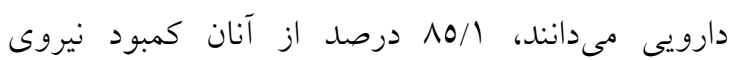

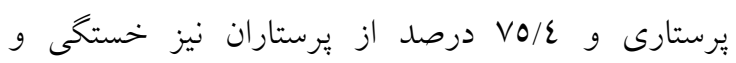

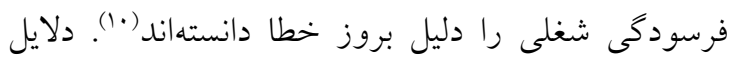
ذكر شده از نظر اهميت، در يزوهش حاضر، به عنوان لرون سومين دليل خطاهاى دارويى بودهاند. يافتهاى مطالعات كيفى انجام شده در استراليا بيان مىدارند كه مطابق ادراى يرستاران، دلايل بروز خطاى دارويى مشتمل بر تفاوت

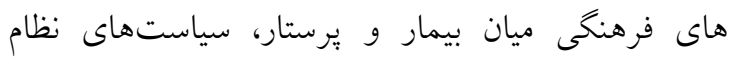

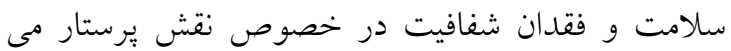
باشند. به علاوه، اين دلايل با محيط فيزيكى نامناسب و

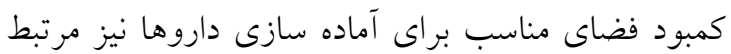

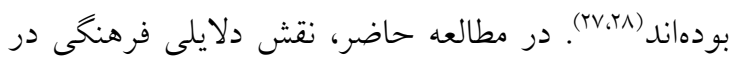

\section{بحث و نتيجه كيرى}

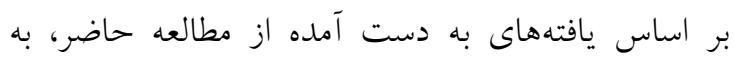

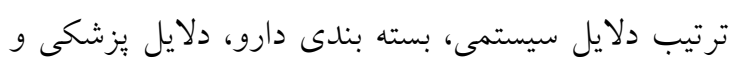

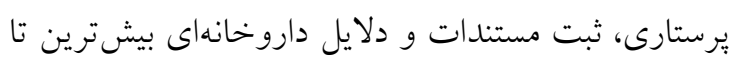

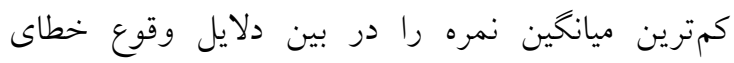
دارويى كسب كردند. براى بررسى دلايل سيستمى، كويه

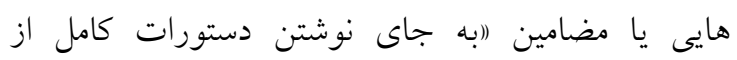

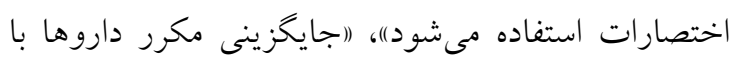

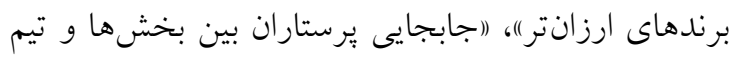

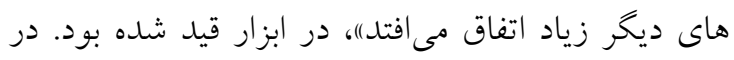

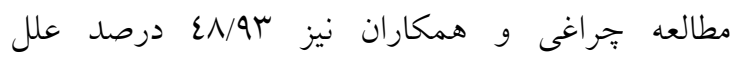
خطاهاى دارويى، استفاده از نام هاى اختصارى بود (r) كه با نتيجه مطالعه حاضر هم راستا مىباشد. در مطالعه

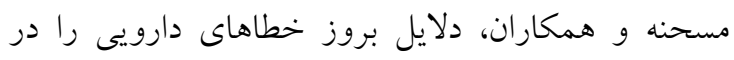

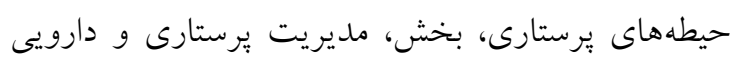

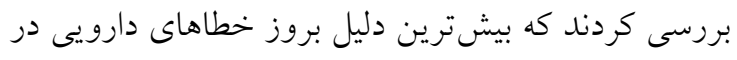
هر حيطه شامل خستخى ناشى از كار اضافى، تراكم زياد

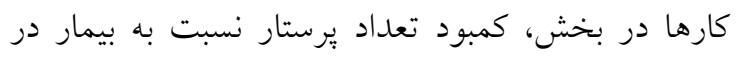

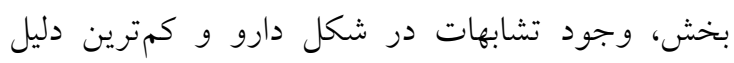

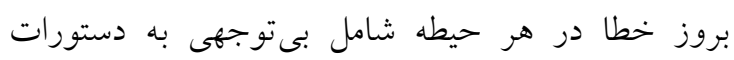

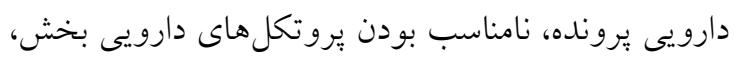

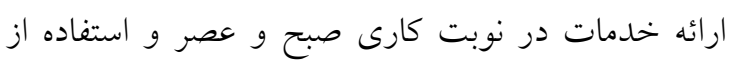

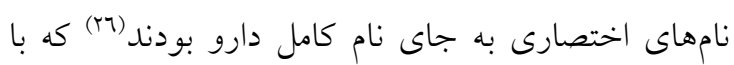
نتيجه مطالعه حاضر متفاوت است. اين تفاوت مى تواند به به بهاري

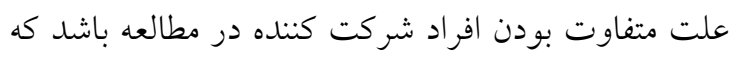

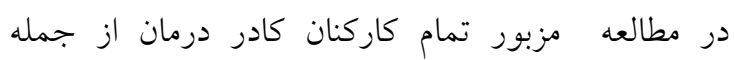

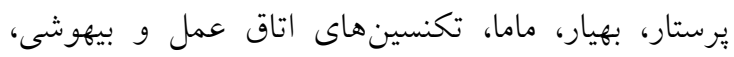

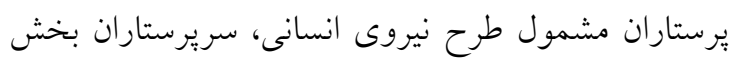

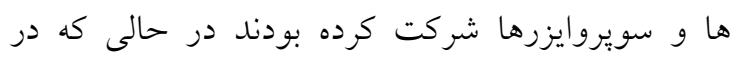

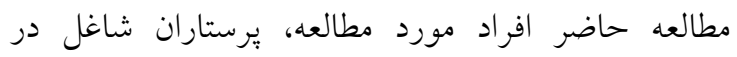
بخشهاى CCU و CU بودند. متفاوت بودن ابزار كردآورى دادهها نيز مىتواند يكى از دلايل تفاوت در دو

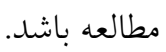


در راستاى كزارش خطا مطرح مىباشند كه بايد مورد توجه يزوهشخران قرار كيرند.

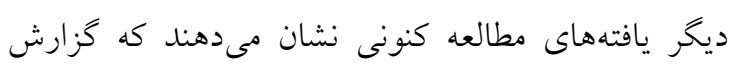
خطاى دارويى وريدى درصد بالاترى نسبت به خطاى بهى دهاى

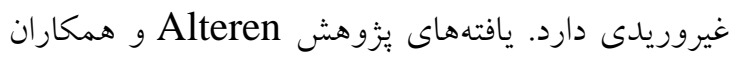
در نروز بيان داشت كه يك سوم از يرستاران تحت مطالعه، خطاى دارويى وريدى را كزارش نمودهاند (T).

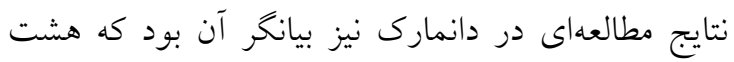
درصد از برستاران مورد بررسى، خطاهاى دارويى وريدى

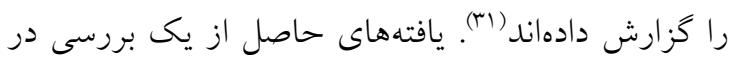
هلند بيان نمود كه از ميان ror7 مورد تزريق وريدى

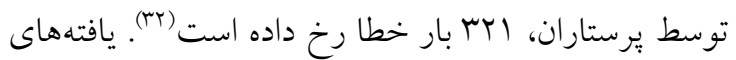

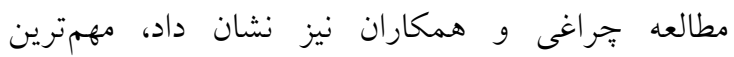

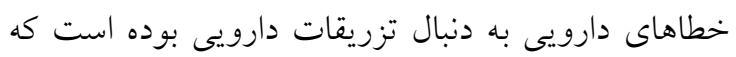

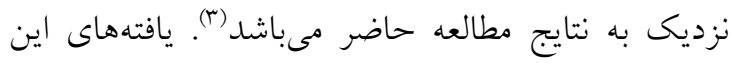
بخش از مطالعه بيانخر اهميت توجه به نحوه دارو دادن

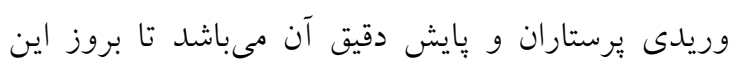
خطاها به حداقل برسد.

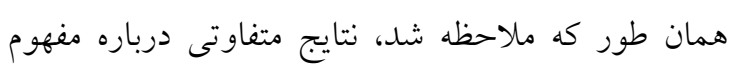

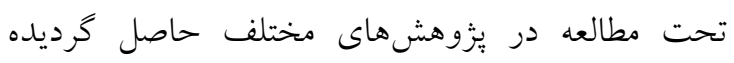
است. مطالعه مرور نظاممند كه توسط اسيرى و همكاران بر روى •7 مطالعه مرتبط در اين زمينه انجام شده، نشان

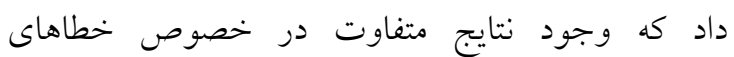

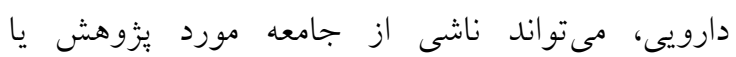
ابزارهاى مورد استفاده باشد (بT).

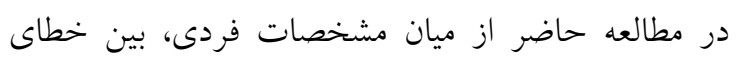
دارودهى با متغيرهاى سابقه كار در بخش ويزه و سن

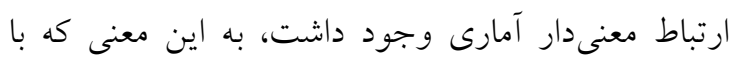

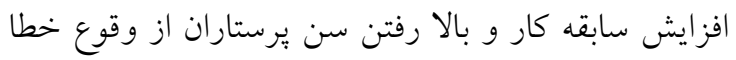
كاسته شده است. در مطالعه قربان زاده و همكاران نيز هم

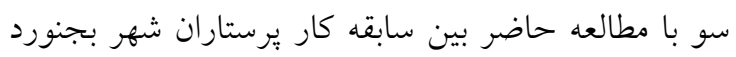

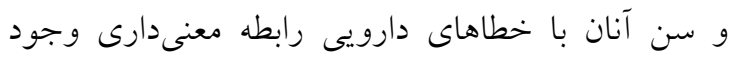

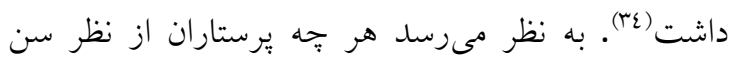
تقويمى و سن كارى، زمان بيشترى را طى مى كنند، به
بروز خطاى دارويى مشخص نيست اما با توجه به اينكه

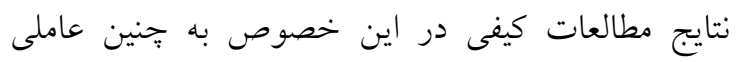

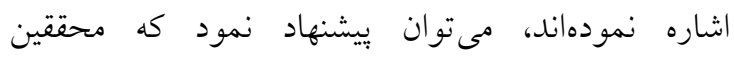

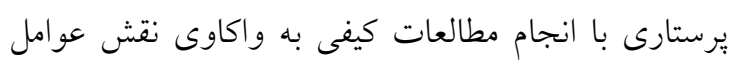
فرهنكى در بروز اين خطاها بيردازند.

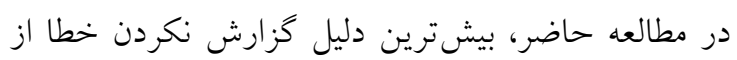
سوى پرستاران دلايل مديريتى و كمترين دليل عدم

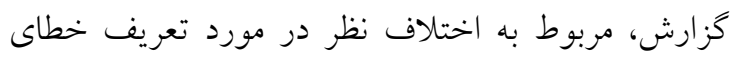

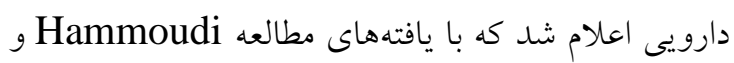

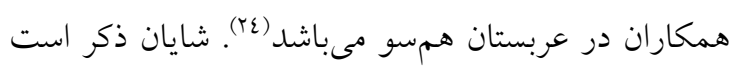
كه در هر دو مطالعه از يكى برسشنامه استفاده شده است.

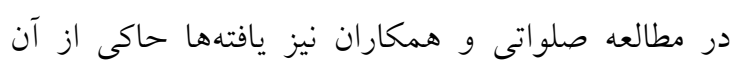

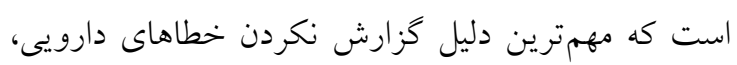

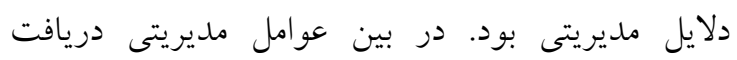
نكردن بازخورد مثبت از طرف مسئولين يرستارى به دنبال

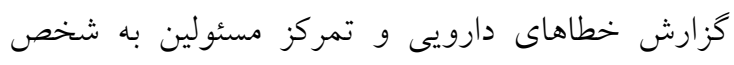

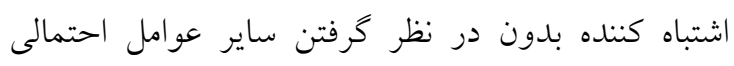
دخيل در بروز خطاها بيشترين اهميت را از ديدكاه

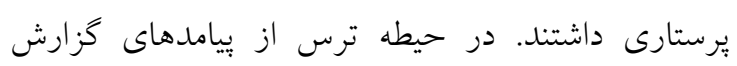

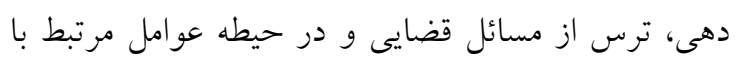

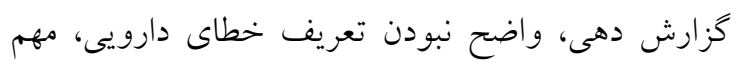

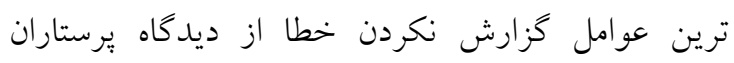
بود (19)، در حالى كه نتيجه مطالعه ابراهيم يور و همكاران

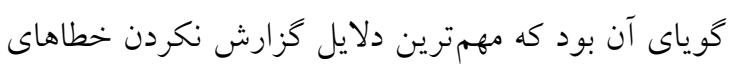

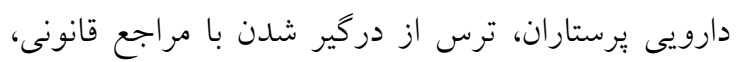

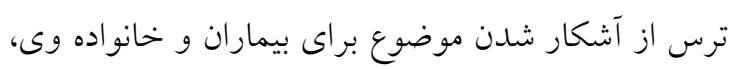

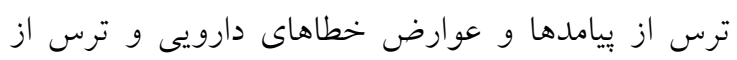

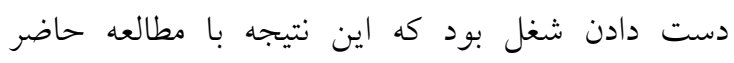

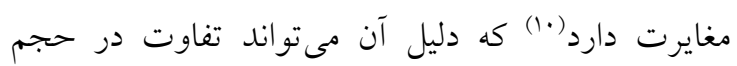

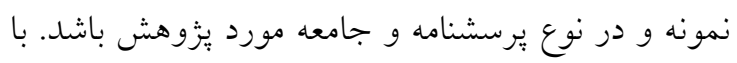
اين حال، يافتههاى مطالعهاى در ايالات متحده آمريكا،

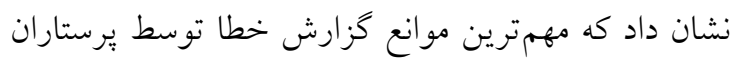

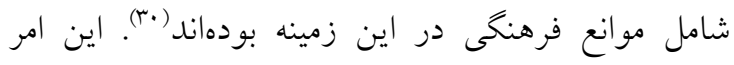

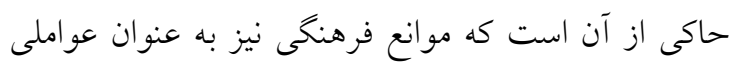


ادراكات يرستاران درباره خطاهاى دارويى دست يافت.

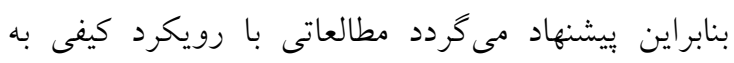

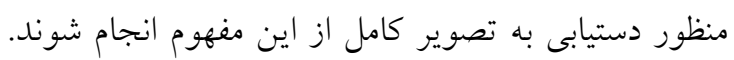

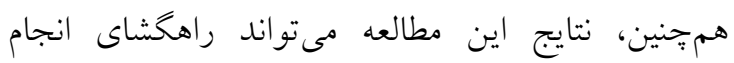

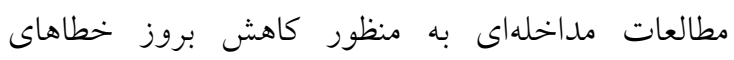
دارويى براى برستاران باشد. اين مطالعه محدوديتهايى مهني

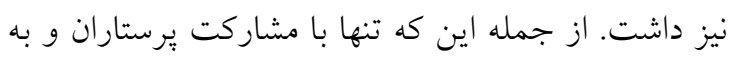

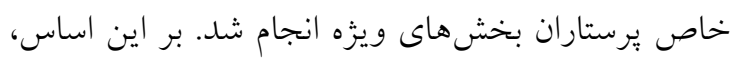

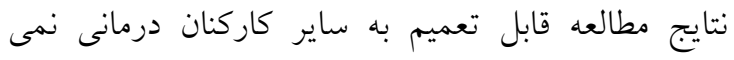

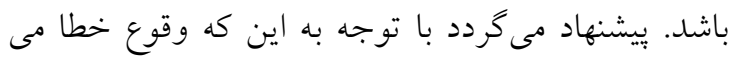

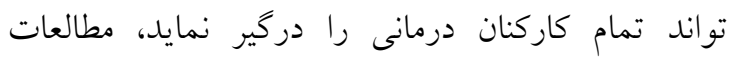
كستردهترى در اين خصوص صورت يذّيرد.

تعارض منافع:هيج گونه تعارض منافع توسط نويسندگان

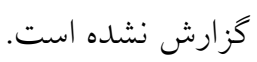

\section{تقدير و تشكر}

مقاله حاضر بركرفته از پِيايان نامه كارشناسى ارشد

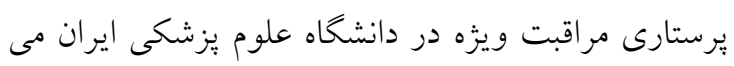

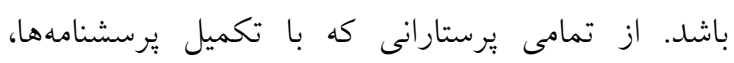

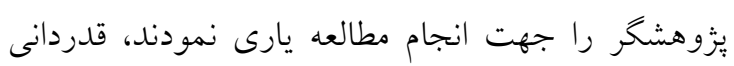
مىشود.
همان نسبت نيز بيشتر بر محيط كارى خود تسلط ييدا

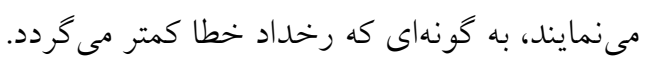

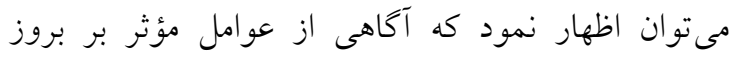

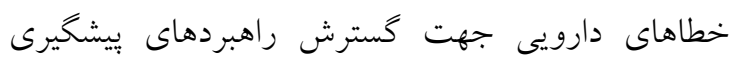

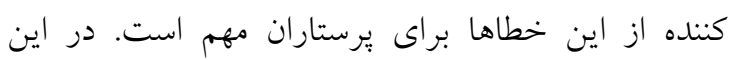

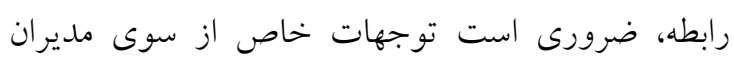

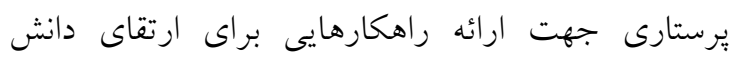

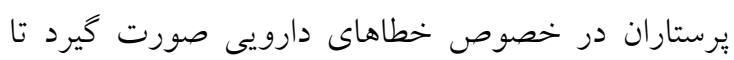

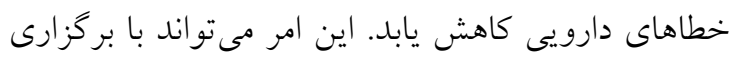

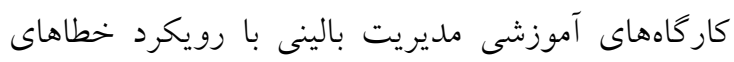

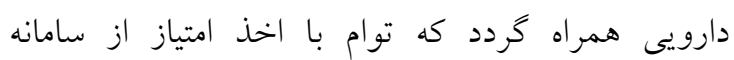
آموزش مداوم براى يرستاران نيز باشد. در همين زمينه،

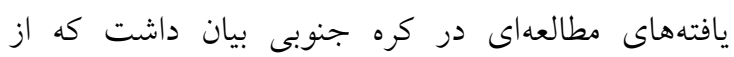

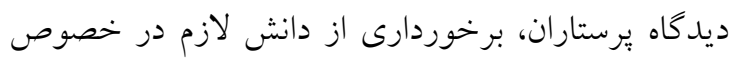

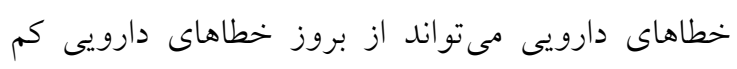

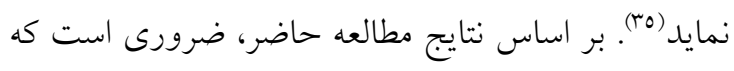

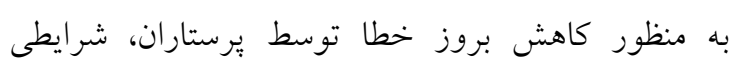
ايجاد شود تا از بروز خطاهاى سيستمى در بيمارستان بـان

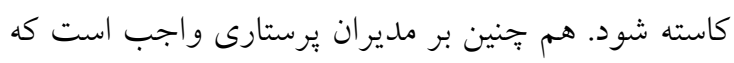

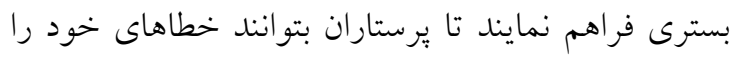

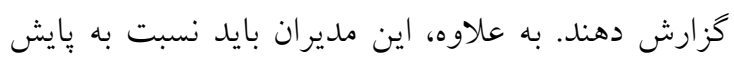

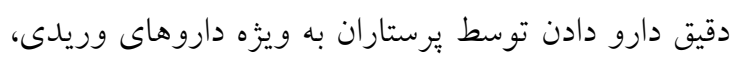
اقدام نمايند.

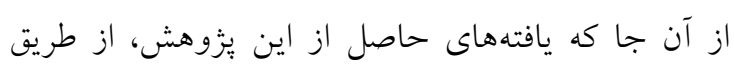

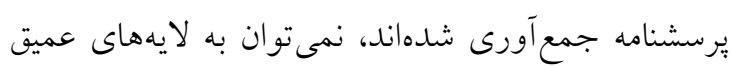

\section{References}

1. Marshall JC, Bosco L, Adhikari NK, Connolly B, Diaz JV, Dorman T, Fowler RA, Meyfroidt G, Nakagawa S, Pelosi P, Vincent JL. What is an intensive care unit? A report of the task force of the World Federation of Societies of Intensive and Critical Care Medicine. J Crit Care. 2017;37:270-6.

2. Farzi S, Irajpour A, Saghaei M, Ravaghi H. Causes of medication errors in intensive care units from the perspective of healthcare professionals. J res pharm pract. 2017;6(3):158-65.

3. Cheraghi MA, Nikbakhat Nasabadi AR, Mohammad Nejad E, Salari A, Kheyli EK, Roghayeh S. Medication errors among nurses in intensive care units (ICU). Journal of Mazandaran University of Medical Sciences. 2012;21(1):115-9. [Persian] 
4. Diessl S, Verburg FA, Hoernlein A, Schumann M, Luster M, Reiners C. Evaluation of an internet-based e-learning module to introduce nuclear medicine to medical students: a feasibility study. Nucl Med Commun. 2010;31(12):1063-7.

5. Rohde E, Domm E. Nurses' clinical reasoning practices that support safe medication administration: An integrative review of the literature. J clin nurs. 2018;27(3-4):e402-11.

6. Alteren J, Hermstad M, White J, Jordan S. Conflicting priorities: observation of medicine administration. J Clin Nurs. 2018;27(19-20):3613-21.

7. Mozafari M, Borji M. Evaluating the rate of nurses' errors in administration of medication orders in general departments of hospitals in the city of Ilam. Iranian Journal of Nursing Research. 2017;12(5):21-6. [Persian]

8. Shahrokhi A, Ebrahimpour F, Ghodousi A. Factors effective on medication errors: A nursing view. J Res Pharm Pract. 2013;2(1):18-23.

9. Jember A, Hailu M, Messele A, Demeke T, Hassen M. Proportion of medication error reporting and associated factors among nurses: a cross sectional study. BMC nursing. 2018;17(1):9.

10. Kiymaz D, Koç Z. Identification of factors which affect the tendency towards and attitudes of emergency unit nurses to make medical errors. J Clin Nurs. 2018;27(5-6):1160-9.

11. Ebrahimipour H, Mahmoudian P, Hosseini E, Tabatabaii S, Badiee S, Vafaee-Najar A, Haghighi $\mathrm{H}$. Factors associated with the incidence of medication errors and nurses' refusal to error reporting. Journal of Health Based Research. 2016;1(3):241-53.[Persian]

12. Taheri HabibAbadi E, Noorian M, Rassouli M, Kavousi A. Nurses' Perspectives on Factors Related to Medication Errors in Neonatal and Neonatal Intensive Care Units. Iran Journal of Nursing (2008-5923). 2013;25(80) :65-74. [Persian]

13. Raeisi P, Hasanzade E, Geraie M, Kabani J, Kakemam E, Mohammadi S. Occupational Stress and Cognitive Failure of Nurses in Clinical Errors in the Teaching Hospitals Affiliated to Iran University of Medical Sciences. Iran Journal of Nursing. 2018;31(113):52-61. [Persian]

14. Melnyk BM, Orsolini L, Tan A, Arslanian-Engoren C, Melkus GD, Dunbar-Jacob J, Rice VH, Millan A, Dunbar SB, Braun LT, Wilbur J. A national study links nurses' physical and mental health to medical errors and perceived worksite wellness. J Occup Environ Med. 2018;60(2):126-31.

15. Rezaiamin A, Pazokian M, Zagheri Tafreshi M, Nasiri M. The relationship between work commitment, dynamic, and medication error. Clinical nursing research. 2018;27(6):660-74.

16. Matti N, Nguyen MN, Mosel C, Grzeskowiak LE. Utilization of neonatal medication error prevention strategies: a clinical practice survey of Australian and New Zealand neonatal units. Ther Adv Drug Saf. 2018;9(11):609-17.

17. Dirik HF, Samur M, Seren Intepeler S, Hewison A. Nurses' identification and reporting of medication errors. J Clin Nurs. 2019;28(5-6):931-8.

18. Ragau S, Hitchcock R, Craft J, Christensen M. Using the HALT model in an exploratory quality improvement initiative to reduce medication errors. Br J Nurs. 2018;27(22):1330-5.

19. Soori S, Rostami Z, Aghilidehkordi G. Occurrence and reporting of nurses' medication errors in a teaching hospital in Isfahan. Journal of Health Administration. 2019;21(74):75-86. [Persian]

20. Rahimi F, Ahangar zadeh Rezaei S, Baghaei R, Faezi A. Factors affecting the incidence of medication errors in nursing staff of Besat Hospital in Sanandaj City in 2011. Scientific Journal of Nursing, Midwifery and Paramedical Faculty. 2016;1(3):12-7. [Persian]

21. Hermanspann T, van der Linden E, Schoberer M, Fitzner C, Orlikowsky T, Marx G, Eisert A. evaluation to improve the quality of medication preparation and administration in pediatric and adult intensive care units. Drug Healthc Patient Saf. 2019;11:11-18.

22. Athanasakis E. A meta-synthesis of how registered nurses make sense of their lived experiences of medication errors. J Clin Nurs. 2019;28(17-18):3077-95.

23. Wakefield BJ, Uden-Holman T, Wakefield DS. Development and validation of the medication administration error reporting survey. Agency for Healthcare Research and Quality Rockville Md. Advances in Patient safety. 2005; 41:475-88.

24. Hammoudi BM, Ismaile S, Abu Yahya O. Factors associated with medication administration errors and why nurses fail to report them. Scand J Caring Sci. 2018;32(3):1038-46. 
25. You MA, Choe MH, Park GO, Kim SH, Son YJ. Perceptions regarding medication administration errors among hospital staff nurses of South Korea. International journal for Quality in health care. 2015;27(4):276-83.

26. mosahneh A, ahmadi B, akbarisari A, rahimi foroshani A. Assessing the Causes of Medication Errors from the Nurses।'Viewpoints of Hospitals at Abadan City in 2013. Journal of Hospital. 2016;15(3):41-51. [Persian]

27. Khalil H, Lee S. Medication safety challenges in primary care: Nurses' perspective. J Clin Nurs. 2018;27(9-10):2072-82.

28. Alomari A, Wilson V, Solman A, Bajorek B, Tinsley P. Pediatric nurses' perceptions of medication safety and medication error: a mixed methods study. Compr Child Adolesc Nurs. 2018;41(2):94-110.

29. Salavati S, Hatamvand F, Tabesh H. Nurses' Perspectives on Causes of Medication Errors and Non-Reporting at ED. Iran Journal of Nursing. 2012;25(79):72-83. [Persian]

30. Rutledge DN, Retrosi T, Ostrowski G. Barriers to medication error reporting among hospital nurses. J Clin Nurs. 2018;27(9-10):1941-9.

31. Rishoej RM, Almarsdóttir AB, Thybo Christesen H, Hallas J, Juel Kjeldsen L. Identifying and assessing potential harm of medication errors and potentially unsafe medication practices in paediatric hospital settings: a field study. Ther Adv Drug Saf. 2018;9(9):509-22.

32. Schutijser BC, Klopotowska JE, Jongerden IP, Spreeuwenberg PM, De Bruijne MC, Wagner C. Interruptions during intravenous medication administration: a multicentre observational study. $J$ Adv Nurs. 2019;75(3):555-62.

33. Assiri GA, Shebl NA, Mahmoud MA, Aloudah N, Grant E, Aljadhey H, Sheikh A. What is the epidemiology of medication errors, error-related adverse events and risk factors for errors in adults managed in community care contexts? A systematic review of the international literature. BMJ open. 2018;8(5):e019101.

34. Ghorbanzadeh M, Gholami S, Sarani A, Badeli F, Nasimi F. The Prevalence, Barriers to Medication Error Reports, and Perceptions of Nurses toward the Causes of Medication Errors in the Hospitals Affiliated to North Khorasan University of Medical Sciences, Iran. Iran Journal of Nursing. 2019;32(117):58-68. [Persian]

35. Kim MS, Kim CH. Canonical correlations between individual self-efficacy/organizational bottom-up approach and perceived barriers to reporting medication errors: a multicenter study. BMC Health Serv Res. 2019;19(1):495. 